\title{
On Human Experimentation: A Perspective of China's Criminal Law
}

\section{Chang-Qiu Liu}

Law Institute, Shanghai Academy of Social Sciences, Shanghai, China.

Email: shangujushi@sina.com

Received June $5^{\text {th }}$, 2012; revised July $8^{\text {th }}$, 2012; accepted July 20 ${ }^{\text {th }}, 2012$

\begin{abstract}
Human experimentation is important to the development of life science. There are so many problems brought about by human experimentation, which should be paid more attention to by law in order to protect the right of the subject. International as well as domestic laws are enacted in order to beat the illegitimate human experiment, while criminal countermeasures should be taken to redeem the failure of common legal measures, especially for China.
\end{abstract}

Keywords: Human Experimentation; Crime; Criminal Law

\section{Introduction}

Human experimentation, also called human experiment, is an experimentation done on human body through scientific methods to attain certain anticipated goals. Human experimentation is indispensable to the progress of life science. Just as one scholar points out, "Research on human subjects is the only way in which we can satisfactorily establish the effectiveness and safety of medical treatment [1, p. 448].” Although we can not say life science would stop developing without human experimentation, we can allege that the development of life science will slow down soon without human experimentation. Yet as one of the indispensable elements of life science research, human experimentation also brings about many legal problems, which need law intervention. Among these problems there are the ones that should be regulated by criminal law. In China as well as other countries, these problems become more and more urgent to be treated with the rapid development of biotechnology.

\section{The Challenges Brought by Human Experimentation}

Human experimentation plays an important role in the development of life science. It has become a common knowledge that human experiment is beneficial to life science and human's health after Edward Jenner, an England doctor, found the way to prevent smallpox through implanting cowpox into a healthy boy. The success of his

*I want to express my sincere thanks to Doctor Xiuqing Shen of Shandong University, who helped me a lot in correcting the grammar mistakes of this article. experiment declared a lifelong immunity of human to smallpox and helped human experiment attain its legitimacy [2, p. 412].

Yet human experimentation didn't always come into people's eyes with a good image. It has also been taken on an indecent role from time to time. The human experiment done in the Second World War by Nazi doctors as well as Japanese 731 troops are good cases in point. During the World War II, the military doctors of Nazi did brutal experiments on prisoners as well as the Jews and so on in the name of medical science. Many prisoners died of such experiments. While in the east, more ruthless crimes happened. In order to achieve victory in the fascist war, the Japanese army established many experimental factories to develop biochemistry weapons, where they did all sorts of brutal experiments on Chinese, Russian, Korean subject and so on. Thousands of people were persecuted in such experiments [2, p. 414].

Besides the miserable experimentations in the World War II, there are still many illegitimate human experiments in the history of life science. In 1947, an experiment assisted by American government was done without informed consent on 18 persons to determine how long the high-tech beryllium would be maintained after it was injected into human body. In 1946-1948, U.S. government medical researchers did a research, in which scientists deliberately infected Guatemalan research subjects with syphilis to study how well penicillin worked [3]. In 1996, Pfizer Inc. of Unite States did a pharmaceutical experiment on nearly two hundred boys who had got meningitis to test healing effect of Trovan. Eleven of these boys died in this experiment while the left 181 boys 
suffered a lot from the experiment, almost all of them disabled [4, p. 308]. In October ten, 2006, four Israel senior doctors were reported to have done a medical experiment on hundreds of old people which caused thirteen of them died.

Though it is important to the development of life science and helpful to the health of human beings in most cases, human experiments also produce offences as some of the experiments stray away from bioethical principles for irrational purposes [5, p. 162]. The illegal human experiments we mentioned above are just cases in point. Such experiments bring about great challenges to bioethics as well as law. The challenges are very strident to criminal law since it has to face such problems as follows: whether irrational human experiments are maleficent, whether it should intervene with the life science, how to make balance between legitimate human experiments and illegitimate human experiments if it should intervene with the experiment, and so forth. As more and more human experiments take place with the development of biotechnology, these challenges should be regulated properly by criminal law.

\section{Literature Review on Illegitimate Human Experimentation in Law}

As human experiment is done on human body, it evidently produces side effects on the subject, even leading to the death sometimes. Under this background, it has been an urgent problem to probe criminological issues related with human experimentation. Many jurists have done their research on this problem and put forward their suggestions. Among these research, three problems should be paid more attention to: 1) Why human experimentation is legitimate? 2) How to determine whether an illegitimate human experimentation has become a crime? 3) Whether some medical human experimentation with exploratory purpose should be regarded as crimes [6, p. 314]?

As far as I am concerned, the legitimacy of human experimentation lies in the three factors as follows: Firstly, human experimentation contributes to the progress of life science and thus helps people keep as well as regain health, which brings about adequate reasons in bioethics to make people accept doing experiment on themselves. Namely, if a human experiment strays away from the purpose of being beneficial to human themselves, it's sure to be short of legitimacy and is standing on the edge of a crime. Secondly, a legitimate experiment on human being should be based on informed consent by the subject. According to the famous Roman juristic proverb, the human experiment based on informed consent is legal, while it will be an offence without the consent of the victim.

As to the question of whether some medical human experimentation with quest purpose should be regard as crimes, it rests on the risk of the experiment as well as the purpose of the experimenter. If the experimenter does an experiment with high risks which overweigh sufferance of society, he should be viewed as conducting a crime. On the other hand, if the experimenter does the experiment not on the purpose of benefiting people's health, but to insult the indignity of the subject or the indignity of human being, his conduct should also be seen as a crime. Take the operation of brain death for example, since brain death has been accepted as the death criteria of a person by medicine professionals, there's not too much risks in such operations. What's more, there's no insult in the purpose of the operator. Under this circumstance, the operation of a brain death should be viewed as legitimate and legal instead of a crime or an offence.

\section{The Law on Illegitimate Human Experiment}

\subsection{International Law on Illegitimate Human Experiment}

Illegitimate human experiments are prohibited by The Nuremberg Code, which was promulgated in 1947. The Nuremberg Code proclaimed that the voluntary consent of the human subject is absolutely essential and that the experiment should be such as to yield fruitful results for the good of society, unprocurable by other methods or means of study, and not random and unnecessary in nature. In Geneva Convention III and Geneva Convention IV, illegitimate human experimentation is also seen as an international crime. Another important international file is the Declaration of Helsinki, which declared that the purpose of biomedical research involving human subjects must be helpful to improve diagnostic, therapeutic and prophylactic procedures and the understanding of the aetiology and pathogenesis of disease.

\subsection{The Law on Illegitimate Human Experiment in Some Countries}

Illegitimate human experiments are also prohibited by the laws of most countries. And illegitimate human experimentation is even viewed as a crime by the criminal law of some countries. In Japan, German, the United States, as well as some other countries, illegitimate human experiments such as experiments without informed consent are all prohibited. For example, although the question of consent to medical research has not been tested in an English court, any research that involves physical contact would certainly require consent to avoid being a battery. In France, Australia, Slovakia, Macedonian and Serbia, an illegitimate human experimentation will be seen as a crime and will be punished by the 
criminal law.

It's self-evident that most countries have attached great importance to the formulation of illegitimate human experiments. Yet on the whole, only a few countries such as Italy, France, Australia, Slovakia, Macedonian and Serbia have formulated human experimentation in the criminal law straightforwardly, while other countries formulated illegitimate human experimentation only by civil law or administrative law as some scholars worried that prohibition of illegitimate human experimentation would hinder the progress of life science. As far as I'm concerned, such worry is unnecessary, since the aim of the intervention in human experiment by criminal law is only to restrict the seriously unlawful experiments, but not to refrain all human experiments. The legislation on human experimentation should not be halted for the above worry.

\section{Criminal Countermeasures on Illegitimate Human Experimentation of China}

In China, human experimentation laws are urgently needed as there are over eight hundreds of new medical human experiments every year, while only few laws could be used in regulating illegitimate human experiments. In China, the governance on illegitimate human experiments need intervention by criminal law as Chinese people believe that, for some severely illegitimate experiments, only criminal law could help. In the Law on Practicing Doctors of the People's Republic of China enacted in 1998 and China's Good Clinical Practice published in 1996 as well as some other laws, medical research should be conducted based on informed consent. And anyone who does a medical research illicitly would assume criminal liability. But on the other hand, the Criminal Law of the People's Republic of China hasn't established a criminal charge on human experimentation. Restricted by the principle of statutory crime and penalty, which has been adopted by China's criminal law for over fifteen years, China's criminal law plays little role on an illegitimate medical research.

In order to protect the subject more powerfully and safeguard the healthy development of medical professsions, there is an urgent requirement to amend a criminal charge in Criminal Law of the People's Republic of China, which makes it clear to all that illegitimate human experiments are unlawful and whether they should be punished or not.

\section{REFERENCES}

[1] E. Jackson, "Medical Law: Text, Cases and Materials," Oxford University Press, New York, 2006.

[2] X. M. Zhai and R. Z. Qiu, "Outline of Bioethics,” Tsinghua University Press, Beijing, 2005.

[3] L. Villarosa, “The Guatemala Syphilis Experiment’s Tuskegee Roots,” 2010.

http://www.theroot.com/views/tuskegee-study-s-guatemal an-roots

[4] Z. M. Ni and Q. S. Lu, "Introduction of Life Jurisprudence,” China’s Wuhan University Press, Wuhan, 2005.

[5] C. Q. Liu, "Biotechnology Crimes and Their Criminal Countermeasures,” China’s Law Press, Beijing, 2006.

[6] C. Q. Liu, "Research on Life Science and Technology Crime and Modern Theory of Criminal Responsibility and System," China's Shanghai People's Publishing House, Shanghai, 2011. 